\title{
Expression and subcellular localization of the $\mu$-opioid receptor in equine spermatozoa: evidence for its functional role
}

\author{
Maria Albrizio, Antonio Ciro Guaricci, Filippo Maritato, Raffaele Luigi Sciorsci, \\ Gaetano Mari ${ }^{\prime}$, Giuseppe Calamita ${ }^{2}$, Giovanni Michele Lacalandra, Giulio Guido Aiudi, \\ Rosa Minoia, Maria Elena Dell'Aquila and Paolo Minoia \\ Department of Animal Production, University of Bari, Str. Prov. Casamassima Km 3, 70010 Valenzano, Bari, Italy, \\ ${ }^{1}$ Veterinary Clinical Department, University of Bologna, Via Tolara di Sopra 50, 40064 Ozzano dell'Emilia, \\ Bologna, Italy and ${ }^{2}$ Department of General and Environmental Physiology, University of Bari, Bari, Italy
}

Correspondence should be addressed to M Albrizio; Email: m.albrizio@veterinaria.uniba.it

\begin{abstract}
The development of fertilizing ability in sperm cells is associated with changes in the plasma membrane. However, to date the exact nature of sequentially activated primary receptors and channels and the signal transduction pathways derived from these remains elusive. We analyzed the expression and localization of the $\mu$-opioid receptor in equine spermatozoa. A transcript corresponding to the third extracellular loop that selectively binds $\mu$ agonists was amplified, sequenced and compared with the known sequences in humans, rats and cattle. The amplification product showed a high degree of nucleotide conservation. By immunofluorescence, $\mu$-opioid receptor labeling was found on the sperm head and on the tail and disappeared in the acrosomal region of acrosome-reacted sperm cells. Immunoblotting revealed two bands of 50 and $65 \mathrm{kDa}$. Effects of the opioid antagonist naloxone on motility and on viability and capacitation/acrosome reaction were investigated by computerassisted sperm analysis and Hoechst 33258/chlortetracycline (H258/CTC) staining. Progressive motility was significantly reduced after $3 \mathrm{~h}$ incubation in $10^{-3} \mathrm{M}$ naloxone $(P<0.05)$, whereas it increased significantly after $5 \mathrm{~h}$ in $10^{-8} \mathrm{M}$ naloxone $(P<0.05)$. Sperm velocity at $5 \mathrm{~h}$ was significantly reduced by the addition of $10^{-3} \mathrm{M}$ naloxone $(P<0.05)$, but increased significantly in the presence of $10^{-8} \mathrm{M}(P<0.001)$. Curvilinear velocity and amplitude of lateral head displacement in spermatozoa incubated in the presence of naloxone were not indicative of hyperactivation. $\mathrm{H} 258$ /CTC staining showed that $10^{-8} \mathrm{M}$ naloxone significantly stimulated capacitation $(P<0.01)$ after $3 \mathrm{~h}$. However, it had no effect on sperm cell viability and acrosomal status. Overall, this study provides the first evidence that the $\mu$-opioid receptor is expressed in equine spermatozoa and that naloxone significantly affects motility and capacitation.

Reproduction (2005) 129 39-49
\end{abstract}

\section{Introduction}

The production of a fully differentiated and functionally competent sperm cell is the result of a series of coordinated events that begin in the male and culminate in the female genital tract (Hunter 1997, Roser 2001, Yanagimachi 1994). After ejaculation, sperm cells are not immediately capable of fertilizing oocytes. Rather, they must undergo a period of preparation with morphological and functional modifications leading to acrosomal reaction. These modifications of the sperm surface are consequent to intimate endosalpingeal-sperm head interactions, due to the local influence of ovarian endocrine programming in specific regions of the fallopian tube epithelium (Roser
2001, Yanagimachi 2002). Despite investigations on processes occurring at the sperm plasma membrane (Flesch and Gadella 2000) and their derived signal transduction reactions, carried out in recent years (Flesch and Gadella 2000, Baldi et al. 2002), the exact nature of the primary receptors and channels sequentially activated on the sperm plasma membrane remains elusive (Bray et al. 2002). Although a number of intracellular messenger systems were implicated in the complex biochemistry of capacitation and acrosome reaction, it appears that gating of $\mathrm{Ca}^{2+}$ channels and consequent $\mathrm{Ca}^{2+}$ influx play a central role in the cascade of events leading to sperm activation and oocyte fertilization (Ren et al. 2001, Jagannathan et al. 2002). 
Recent studies demonstrated that endogenous opioid peptides (EOPs) can influence $\mathrm{Ca}^{2+}$ turnover and, by acting on voltage-gated $\mathrm{Ca}^{2+}$ channels, create $\mathrm{Ca}^{2+}$ oscillations within the cell and thus modify downstream $\mathrm{Ca}^{2+}$-dependent cellular activity (Bourinet et al. 1996). Like all other G-protein-coupled systems, opioid receptors exhibit homologous and heterologous desensitization (review by Minami and Satoh 1995), and therefore their excessive stimulation induces a loss of neuromodulative opioid activity. In the male reproductive tract, opioid receptors have only been reported to date in rat Sertoli cells (Fabbri et al. 1985). Opioid receptors are target molecules for analgesia, reward and many physiological functions of opiates. In particular, the $\mu$-receptor is the primary site of action of several EOPs, including $\beta$-endorphin (Zadina et al. 1997) and for most of the therapeutic effects and side effects of morphine. This receptor has been reported to modulate somatic $\mathrm{Ca}^{2+}$ channel currents in mouse peri-aqueductal gray neurons (Connor et al. 1999). Naloxone (Nx) is an opioid receptor antagonist (Reisine and Pasternak 1996) that has been shown to have opposite effects depending on its concentration, suggesting that it may function as a partial agonist at high concentrations (Feigenbaum and Howard 1997). It has also been shown to revert the opioid agonistdependent modulatory action of the $\mu$-opioid receptor on ion channels and second-messenger effectors (Spivak et al. 1997).

Recent studies from our unit demonstrated that both $\beta$-endorphin and $\mathrm{Nx}$ modify intracellular calcium concentration $\left(\left[\mathrm{Ca}^{2+}\right]_{\mathrm{i}}\right)$ and confirmed the concentration-dependent dual effect of $\mathrm{Nx}$ in a renal epithelial cell line (Di Sole et al. 2001). We demonstrated that the $\mu$-opioid receptor mRNA is expressed in the bovine cumulusoocyte complex and that the $\mu$-opioid receptor, by inducing an increase in $\left[\mathrm{Ca}^{2+}\right]_{\mathrm{i}}$, participates in the cumulus-oocyte-coupled signaling associated with oocyte maturation (Dell'Aquila et al. 2002). The present study focuses the possible role of EOP on equine sperm cell function. Capacitation and acrosome reaction mechanisms have been studied in recent years in stallion spermatozoa (for reviews see Christensen et al. 1996, Odeh et al. 2003). Varner et al. (1987) reported the induction of acrosome reaction in equine spermatozoa by the calcium ionophore A23187 and its morphological characterization. Subsequent studies reported the effectiveness of heparin (Christensen et al. 1996), progesterone (Cheng et al. 1998, Rathi et al. 2003) and platelet-activating factor (Odeh et al. 2003) on capacitation and the acrosome reaction in vitro.

The aim of the present study was to analyze the expression of the $\mu$-opioid receptor on equine sperm cells by molecular, biochemical and cytological investigations and therefore to take an indirect approach to studying the effects of EOPs on the crucial events of sperm physiology.

\section{Materials and Methods}

\section{Media and reagents}

Tyrode medium, with the composition described by Rathi et al. (2001), was used for incubating sperm in control conditions. Antibodies were purchased from Chemicon International (Temecula, CA, USA), Sigma Chemical Co. and Molecular Probes (Leiden, The Netherlands). Oligonucleotide primers were purchased from MWG Biotech (Florence, Italy). Naloxone hydrochloride, A23187, Hoechst 33258 (H258), chlortetracycline (CTC), polyvinylpyrrolidone and all chemicals were purchased from Sigma-Aldrich (Milano, Italy).

\section{Semen sampling and processing}

Semen for the receptor-detection procedure and for motility analysis was collected from stallions located at the Institute for Artificial Insemination at Cadriano (Bologna, Italy). Frozen semen from four stallions was used for reverse transcription (RT)-PCR, Western blot and immunofluorescence detection and fresh semen from three stallions (three ejaculates each) was used for motility analysis. Fresh sperm cells of three ejaculates of a stallion located at the Equine Breeding Center, Masseria San Vincenzo, Monopoli (Bari, Italy) were used for the viability and capacitation/acrosome reaction analyses. For receptor detection, frozen semen $(0.5 \mathrm{ml} / \mathrm{straw})$, at a concentration of $1 \times 10^{8}$ sperm cells $\mathrm{ml}^{-1}$, was rapidly thawed (30 s) in a water bath at $37^{\circ} \mathrm{C}$. After thawing, total motility was $60 \%$ as visualized by bright-field microscopy. Before RNA extraction, Western blot or immunofluorescence, sperm cells were allowed to swim up in Tyrode medium in order to recover motile cells without any contaminant leukocytes or other debris, and visually examined, as described previously (Miller et al. 1999, Ostermeier et al. 2002). Collection of fresh semen was carried out according to ethical guidelines. Semen for motility analysis was collected from stallions (4-10 years old) of proven fertility once a week for 3 weeks (three ejaculates per stallion, total of nine evaluations); semen was collected using an artificial vagina, filtered to remove gel and immediately processed for use. Volume of gel-free fraction, concentration (Densimeter Mod.501; ARS, Chino, CA, USA) and total motility under phase-contrast microscope were recorded for each sample. For motility analysis, semen was processed as reported by Rathi et al. (2001). $2 \mu$ l semen was mixed with $6 \mathrm{ml}$ Tyrode medium and centrifuged in a $15 \mathrm{ml}$ tube at $900 \mathrm{~g}$ for $10 \mathrm{~min}$ to allow removal of seminal plasma. After removal of the supernatant, the pellet was resuspended with Tyrode medium, Tyrode medium with $10^{-3} \mathrm{M} \mathrm{Nx}$ or Tyrode medium with $10^{-8} \mathrm{M} \mathrm{Nx}$ to reach a final sperm concentration of $25 \times 10^{6}$ total sperm $\mathrm{ml}^{-1}$. Collection and processing of semen for capacitation/acrosome reaction analysis was performed with the procedure described above. Ejaculates, collected on three different days, were processed separately. 


\section{RNA extraction and RT-PCR}

RNA was extracted and reverse transcribed by using the Express Direct ${ }^{\mathrm{TM}}$ Kit (Pierce, Rockford, IL, USA). For each reaction, $10 \times 10^{6}$ equine sperm cells were used. Cells were lysed in a two-step procedure that disrupts only the plasma membrane and releases mRNA without contaminating genomic DNA. Released mRNAs were captured directly from the cell lysate by hybridization to oligo(dT) covalently linked to the wells of a $0.2 \mathrm{ml} \mathrm{PCR} \mathrm{tube.} \mathrm{First-}$ strand cDNA was synthesized following the manufacturer's instructions. $50 \mathrm{pmol}$ of each specific primer (forward, 5'-GGTACTGGGAAAACCTGCTG-3'; reverse, 5'-GGTCTCTGGTGTTCTGACGA-3') designed based on the bovine $\mu$-opioid receptor sequence (accession number U89677) were used in the 35-cycle PCR profile consisting of denaturation at $94^{\circ} \mathrm{C}$ for $30 \mathrm{~s}$, annealing at $56^{\circ} \mathrm{C}$ for $30 \mathrm{~s}$ and extension at $72^{\circ} \mathrm{C}$ for $1 \mathrm{~min}$. The amplified product was analyzed on a $1.5 \%(\mathrm{w} / \mathrm{v})$ agarose gel, eluted (QIAquick; Qiagen, Hilden, Germany) and sequenced at the Bio Molecular Research Institute, University of Padova, Padova, Italy, with ABI Prism systems (PE Applied Biosystems, Foster City, CA, USA). The obtained $\mu$-receptor sequence was aligned by the ClustalW program (www.ebi.ac.uk/clustalw) with the known cDNA sequences from human, bovine and rat, obtained from GenBank. The RT-PCR analysis was repeated with semen from four stallions.

\section{Immunofluorescence}

At least $5 \mu$ l of sample semen were smeared on to a slide coated with poly-L-lysine. Duplicate slides were prepared, fixed in $4 \%(\mathrm{w} / \mathrm{v})$ paraformaldehyde and incubated for $30 \mathrm{~min}$ in PBS/1\% (w/v) BSA. A 1:2500 dilution of primary rabbit polyclonal antibody against the third extracellular loop of the mouse $\mu$-opioid receptor (anti-MOR; Chemicon) was applied to test slides and left to react overnight at room temperature in a humidified chamber. Negative controls were not exposed to the primary antibody and were incubated in $\mathrm{PBS} / 1 \%(\mathrm{w} / \mathrm{v}) \mathrm{BSA}$ in the same conditions as the test slides. All slides were incubated for $2 \mathrm{~h}$ at room temperature with an anti-rabbit fluorescein isothiocyanate (FITC)-conjugated IgG secondary antibody (Chemicon) diluted 1:200 in Evans Blue in PBS. Evans Blue was used as a counterstain on all samples. Slides were washed three times in PBS, assembled with mounting medium (20 mM Tris, $\mathrm{pH} 8 / 0.5 \%$ (w/v) n-propylgallate $/ 50 \%(\mathrm{v} / \mathrm{v})$ glycerol), and observed under a Nikon Eclipse TE 2000 inverted microscope equipped with a confocal laser-scanning microscope (C1; Nikon). Imaging was performed using a $488 \mathrm{~nm}$ argon ion laser and a $543 \mathrm{~nm}$ helium/neon laser. A subsequent experiment was carried out to investigate whether the $\mu$-opioid receptor is expressed on the sperm cell after the acrosome reaction. Capacitation and the acrosome reaction were induced by incubation in Tyrode/BSA medium supplemented with $1 \mu \mathrm{M}$ A23187, as described below (see the section on combined H258/CTC staining). The acrosomal status was evaluated by the FITC-conjugated Pisum sativum agglutinin (FITC-PSA). The expression of the $\mu$-opioid receptor was investigated with the procedure described above except that an anti-rabbit tetramethylrhodamine isothiocyanate (TRITC)-conjugated IgG secondary antibody (Molecular Probes) diluted 1:250 in PBS was used. Samples were observed under Nikon Eclipse TE 2000 inverted microscope equipped with a Nikon C1 confocal laserscanning microscope. Imaging was performed using a $488 \mathrm{~nm}$ argon ion laser and a $543 \mathrm{~nm}$ helium/neon laser to simultaneously excite TRITC and FITC fluorochrome.

\section{Membrane preparation, $\mathrm{N}$-deglycosylation and immunoblotting}

The enriched plasma membrane fraction of equine spermatozoa was prepared by suspending sperm cells in ice-cold homogenizing buffer $(0.25 \mathrm{M}$ sucrose $/ 10 \mathrm{mM}$ Tris$\mathrm{HCl}, \mathrm{pH}$ 7.5) with protease inhibitors (1 mM PMSF, $1 \mu \mathrm{g} \mathrm{ml}^{-1}$ leupeptin and $1 \mu \mathrm{g} \mathrm{ml}^{-1}$ pepstatin) as described previously (Calamita et al. 2001). For the immunoblotting experiments, samples were denatured for $4 \mathrm{~min}$ at $90^{\circ} \mathrm{C}$ and run on a $13 \%(\mathrm{w} / \mathrm{v})$ polyacrylamide gel $(60 \mu \mathrm{g} / \mathrm{well})$. Separated proteins were electrotransferred on to Immobilon-P membranes (Millipore, Bedford, MA, USA). After transfer, the membrane was blocked with Blotto $(20 \mathrm{mM}$ Tris- $\mathrm{HCl}, \mathrm{pH} 7.5 / 0.15 \mathrm{M} \mathrm{NaCl} / 1 \%$ (v/v) Triton-X100) containing $5 \%(\mathrm{w} / \mathrm{v})$ non-fat dry milk (blocking buffer) for $1 \mathrm{~h}$ and then incubated with rabbit polyclonal anti-MOR antibody (Chemicon) diluted 1:5000 in blocking buffer. After washing $(4 \times 15 \mathrm{~min})$ in blocking buffer, the membrane was incubated for $1 \mathrm{~h}$ with peroxidase-conjugated goat anti-rabbit $\operatorname{lgG}$ antibody (Sigma). After washing $(2 \times 10 \mathrm{~min})$ in blocking buffer and in Blotto $(3 \times 10 \mathrm{~min})$, blots were revealed for peroxidase activity by enhanced chemiluminescence (ECL Plus kit; Amersham) as described by Calamita et al. (2001). For $\mathrm{N}$-glycosidase $\mathrm{F}$ (PNGase F) digestion, $60 \mu \mathrm{g}$ of the enriched membrane fraction were incubated overnight at room temperature in the presence of $2 U$ PNGase $F$ (Boehringer Mannheim, Mannheim, Germany). The enzymatic reaction was stopped by adding one volume of $2 \times$ Laemmli buffer and boiling the resulting mixture at $90^{\circ} \mathrm{C}$ for $4 \mathrm{~min}$. Samples were then analyzed by immunoblotting as described above. Immunoblotting experiments to check the enzymatic activity of PNGase F were performed by using affinity-purified antibodies to rat aquaporin-1 (AQP1; Alpha Diagnostic International, San Antonio, TX, USA), as reported by Smith and Agre (1991).

\section{Motility analysis}

In order to examine the motility parameters of spermatozoa incubated in the presence of $\mathrm{Nx}$, samples from each treatment (control, $10^{-3} \mathrm{M} \mathrm{Nx}, 10^{-8} \mathrm{M} \mathrm{Nx}$ ) and time point $(0,3$ and $5 \mathrm{~h})$ were analyzed using a Hamilton Thorne Research Motility Analyzer (HTM model 7.5; Hamilton Thorne, Beverly, MA, USA). The Hamilton 
Thorne CASA system was programmed as reported previously by Rathi et al. (2001): frames acquired, 20; frame rate, 25/s; minimum contrast, 8 ; minimum size, 6; low/high-size gates, 0.5-1.8; low-/high-intensity gates, 0.5-1.8; non-motile head size, 13; non-motile intensity, 25; medium path velocity (VAP) value, 25; low VAP value, 9; slow cells motile, no; threshold straightness (STR), 80. A 2X-CEL dual-sided analysis chamber (depth, $20 \mu \mathrm{m}$ ) and 2X-CEL cover glass for use with a $20 \mu \mathrm{m}$ chamber (Hamilton Thorne Research) was used for analysis. A total of 181 motile sperm cells were analyzed. Total motility, progressive motility, velocity, curvilinear velocity $(\mathrm{VCL})$ and amplitude of lateral head displacement (ALH) were examined.

\section{Combined H258/CTC staining}

Samples containing $25 \times 10^{6}$ cells $\mathrm{ml}^{-1}$ were divided further into four portions, one of which was supplemented with A23187 to a final concentration of $1 \mu \mathrm{M}$ and two of which were supplemented with $\mathrm{Nx}$ to final concentrations of $10^{-3}$ and $10^{-8} \mathrm{M}$; the fourth portion, with no further additive, was used as a control. All portions were incubated at $37^{\circ} \mathrm{C}$ under $5 \% \mathrm{CO}_{2}$. Aliquots $(200 \mu \mathrm{l})$ of each sample were examined, at 0,3 and $5 \mathrm{~h}$ after incubation, to evaluate viability and state of capacitation/acrosome reaction assessed by $\mathrm{H} 258 / \mathrm{CTC}$ staining as described by Neild et al. (2003). Briefly, a stock solution of H258 was made by dissolving $10 \mathrm{mg}$ in $100 \mu$ l distilled water. It was wrapped in foil and kept at $4{ }^{\circ} \mathrm{C}$. For use, $1 \mu$ of the stock solution was diluted with $10 \mathrm{ml}$ protein-free medium and kept at $4{ }^{\circ} \mathrm{C}$. The fixative was made by mixing $1: 1(\mathrm{v} / \mathrm{v})$ $25 \%$ glutaraldehyde and $1 \mathrm{M}$ Tris, $\mathrm{pH}$ 7.4. The CTC solution was made of $0.75 \mathrm{mM} \mathrm{CTC}$ and $5 \mathrm{mM}$ L-cysteine in chilled CTC buffer containing $20 \mathrm{mM}$ Tris and $130 \mathrm{mM}$ $\mathrm{NaCl}, \mathrm{pH}$ 7.8. A $198 \mu \mathrm{l}$ aliquot of spermatozoal suspension was removed from each treatment and incubated for 2 min with $2 \mu \mathrm{l} \mathrm{H} 258$ solution. Excess dye was removed by layering the mixture over $500 \mu \mathrm{l}$ of $2 \%(\mathrm{w} / \mathrm{v})$ polyvinylpyrrolidone in PBS and centrifuging at $900 \mathrm{~g}$ for $5 \mathrm{~min}$. The supernatant was discarded and the pellet resuspended in $45 \mu \mathrm{l}$ Tyrode solution. A $45 \mu \mathrm{l}$ volume of the CTC solution and $8 \mu \mathrm{l}$ fixative were added to each of the samples and mixed. A $4 \mu \mathrm{l}$ droplet of the fixed and stained sample of spermatozoa was placed on a microscope slide with a droplet of antifade, a coverslip was applied and sealed on to the slide using nail varnish. Samples were observed with a Nikon E600 microscope under epifluorescence illumination using $346-460 \mathrm{~nm}$ (UV-2A) and $450-630 \mathrm{~nm}$ (B-3A) excitation/emission filters for $\mathrm{H} 258$ and CTC, respectively. Spermatozoa were classified as: dead (D) when nuclei showed bright blue fluorescence over the sperm head (cells recorded as dead were not assessed for their CTC-staining pattern); live non-capacitated (L/NC) when bright green fluorescence was distributed uniformly over the entire sperm head, with or without a stronger fluorescent line at the equatorial segment; live capacitated (L/C) when they showed green fluorescence over the acrosomal region and a dark post-acrosome; or live acrosome reacted (L/AR) when sperm showed a mottled green fluorescence over the head, green fluorescence only in the post-acrosomal region or no fluorescence on the head. At least 200 spermatozoa were scored per slide.

\section{Statistical analysis}

Data concerning the viability and capacitation/acrosome reaction were analyzed by the following linear model (SAS 1988): $y_{i j k}=m+T_{\mathrm{i}}+T R_{\mathrm{j}}+e_{\mathrm{ijk}}$ where $y_{\mathrm{ijk}}$ is the dependent variable (for each time; percentage of $A R, C, N C$ and $\mathrm{D}$ over the total counted cells); $T_{\mathrm{i}}$ is the fixed effect of the $i^{\text {th }}$ time (two levels, 3 and $5 \mathrm{~h}$ from the beginning of the incubation); $T R_{\mathrm{j}}$ is the fixed effect of the $j^{\text {th }}$ treatment (four levels, control, ionophore, $10^{-3} \mathrm{M} \mathrm{Nx}$ and $10^{-8} \mathrm{M} \mathrm{Nx}$ ); $e_{\mathrm{ijk}}$ is the residual error; and $m$ is the overall mean. Student's t test (Statistics for Windows, Stat Soft Inc., Tulsa, Oaklahoma, USA) was used to compare the motility of sperm cells incubated in control conditions with that of Nx-treated samples. Differences were taken to be statistically significant when $P<0.05$.

\section{Results \\ Detection of the $\mu$-opioid receptor}

We first demonstrated the presence of the $\mu$-opioid transcript in equine spermatozoa by using an RT-PCR approach. Since the genomic structure and sequence of the equine gene coding for the $\mu$-opioid receptor are still unknown, primers were designed on the most conserved region within the third exon of the human, rat and bovine $\mu$-opioid receptor genes. RT-PCR led to the amplification of a $441 \mathrm{bp}$ fragment of DNA encoding a region encompassing the third extracellular loop of the human brain $\mu$-opioid receptor chain that selectively binds $\mu$ agonists (Xue et al. 1995). The expected $441 \mathrm{bp}$ amplification product for the $\mu$-opioid receptor gene was detected (Fig. 1, lane 2) after $1.5 \%(\mathrm{w} / \mathrm{v})$ agarose-gel electrophoretic separation. For each RT-PCR reaction, a negative control, omitting reverse transcriptase, was performed (Fig. 1, lane 1). Moreover, genomic DNA from equine sperm cells was added to the PCR tube containing the covalently attached oligo(dT) and PCR was performed as above. No product was obtained, thus demonstrating that the oligo(dT) did not retain any contaminant DNA (results not shown).

The RT-PCR product was subjected to automated DNA sequencing to confirm its homology to the known $\mu$ sequences. Fig. 2 shows the obtained equine sequence of the amplified tract of the $\mu$-opioid receptor gene. The partial equine $\mu$-opioid receptor cDNA sequence has been deposited in GenBank under accession number AJ519535. Comparison with conventional cDNA sequences from human, bovine and rat revealed nucleotide identities of 92,99 and $86 \%$, respectively, thus confirming the high degree of nucleotide conservation of the examined region. 


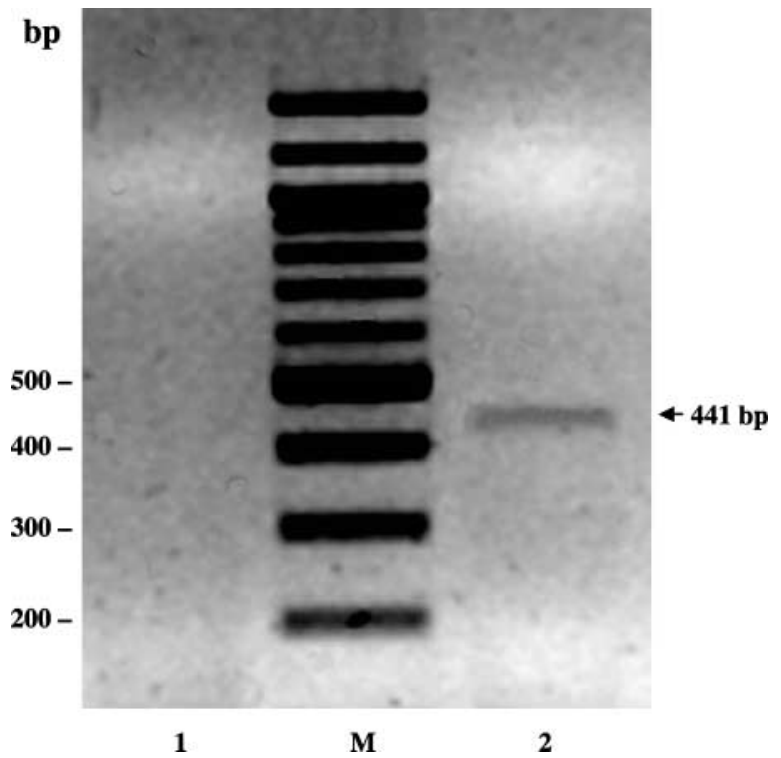

Figure 1 Agarose gel electrophoresis of the RT-PCR product for equine $\mu$-opioid receptor. Lane 2, 441 bp amplified fragment; lane 1, negative control obtained in the absence of reverse transcriptase; lane M, 100 bp DNA ladder marker. Results shown are representative of three separate experiments.

\section{Immunofluorescence}

The presence of mRNA for the $\mu$-opioid receptor in stallion sperm cells prompted us to evaluate whether mature spermatozoa contain the corresponding protein product. Hence, we used indirect immunofluorescence to define the subcellular localization of the sperm $\mu$-opioid receptor in the equine sperm cell by using a rabbit polyclonal antibody prepared against the third extracellular loop of the mouse $\mu$-opioid receptor. As seen in Fig. $3 \mathrm{~A}$, positive immunostaining was observed over the acrosomal region of the sperm head and on the tail. Specificity of the immunolabeling was indicated by the lack of immunoreactivity in sperm cells where the primary antibody was omitted (Fig. 3B). A FITC-PSA and an anti-rabbit TRITC-conjugated IgG secondary antibody were used to elucidate the expression of the $\mu$-opioid receptor in AR sperm cells. FITC-PSA is known to stain glycoproteins in the acrosome of permeabilized spermatozoa. Selective staining of the whole acrosome is indicative of unreacted cells, while no staining at all or staining limited to the equatorial segment is characteristic of AR cells. As can be seen, AR sperm cells, not showing FITC-PSA staining on the head (Fig. $3 \mathrm{C}$ ), are also negative for the $\mu$-opioid receptor (Fig. 3D), thus confirming the localization of the receptor on the plasma membrane in the acrosomal region.

\section{Immunoblotting}

Immunoblotting analysis of an equine sperm fraction enriched in plasma membranes was carried out by using the above mouse anti-MOR polyclonal antibodies. This led to the detection of two bands with molecular masses of about 50 and $65 \mathrm{kDa}$ (Fig. 4A). The detected polypeptides were not $\mathrm{N}$-glycosylated as their sizes were not down-shifted after PNGase F treatment (Fig. 4A). No immunoreactivity was noted with the antiserum depleted of its anti-MOR antibodies by preadsorption with a molar excess of the immunizing peptide (negative control, Fig. $4 \mathrm{~B})$. The $50 \mathrm{kDa}$ band was also observed in homogenates prepared from ovine lymphocytes (positive control, Fig. 4C). Parallel immunoblotting experiments using rat AQP1, a membrane protein known to feature an $\mathrm{N}$-linked glycosylation, proved the activity of the PNGase F (Fig. 4D).

\section{Motility analysis}

Sperm motility was analyzed in three stallions, who provided three ejaculates each. Semen was incubated in Tyrode, Tyrode $+10^{-3} \mathrm{M} \mathrm{Nx}$ and Tyrode $+10^{-8} \mathrm{M} \mathrm{Nx}$. Resulting data, expressed as means $\pm \mathrm{SD}$, are reported in Table 1 . Total motility at $0 \mathrm{~h}$ was approximately $56 \%$ and decreased to $50 \%$ after $3 \mathrm{~h}$ incubation, without any significant differences in the three different treatments. Progressive motility was significantly reduced by the addition of $10^{-3} \mathrm{M} \mathrm{Nx}$ after $3 \mathrm{~h}$ incubation $(P<0.05)$, whereas it was significantly increased by the addition of $10^{-8} \mathrm{M} \mathrm{Nx}$ after $5 \mathrm{~h} \quad(P<0.05) ;$ sperm velocity was also significantly affected by the addition of $\mathrm{Nx}$, with a reduction observed at $10^{-3} \mathrm{M}(P<0.05)$ and an increase observed at $10^{-8} \mathrm{M}$ $\mathrm{Nx}(P<0.001)$ after $5 \mathrm{~h}$. VCL was significantly reduced by the addition of $10^{-3} \mathrm{M} \mathrm{Nx}(P<0.01)$ and significantly increased by the addition of $10^{-8} \mathrm{M} \mathrm{Nx}$ after $5 \mathrm{~h}$. Amplitude of lateral head displacement was significantly reduced $(P<0.05)$ by the addition of $10^{-3} \mathrm{M} \mathrm{Nx}$ after $5 \mathrm{~h}$.

\section{Viability and capacitation/acrosomal status assay}

Dead cells stained positive for $\mathrm{H} 258$ were easily distinguished from the live staining pattern (Fig. 5A). The three live CTC-staining patterns could be clearly distinguished and were categorized as L/NC, L/C and L/AR (Fig. 5B, C and $\mathrm{D})$. At time 0 , there was $79 \pm 11 \%$ live spermatozoa (mean \pm SD from the three samples). By incubating control, ionophore- and Nx-treated samples over 3- and 5-h periods, the H258/CTC patterns were found as shown in Fig. 6. The dual-staining method showed that $\mathrm{Nx}$, at the concentration of $10^{-8} \mathrm{M}$, significantly stimulated capacitation $(P<0.01)$ after a 3 -h incubation. Nx had no statistically significant effects on sperm cell viability and acrosomal status, at either $10^{-3}$ or $10^{-8} \mathrm{M}$ and after both incubation times examined. In sperm samples incubated in the presence of A23187, the percentage of NC cells tended to decrease, compared with the control. However, this reduction did not correspond to an increase in the percentages of C or AR sperm cells. The exposure to A23187 induced an increase in the percentage of $\mathrm{D}$ sperm cells after $3 \mathrm{~h}$ incubation with respect to the control, but this did not attain statistical significance $(P=0.09)$; this effect tended to be further evidenced after $5 \mathrm{~h}$. 


\section{Discussion}

To our knowledge, the present study is the first to demonstrate the presence of the $\mu$-opioid receptor transcript and the expression and localization of the protein end product in sperm cells of a mammalian species. In agreement with previous studies on bovine female germ cells (Dell'Aquila et al. 2002), the $\mu$-opioid receptor seems to be involved in the regulation of sperm cell function to some extent. In particular, the present study indicates that $\mu$-opioid receptors may play a role in the control of sperm motility and capacitation.

The weak intensity of the $\mu$-opioid cDNA band amplified by RT-PCR from the stallion sperm total RNA may be related to the fact that mature sperm, being depleted of most cytoplasmic organelles, does not perform transcription and translation processes (Flesch and Gadella 2000); therefore, the population of mRNA detected in sperm cells could be explained as the remnants of untranslated and stored residual molecules from earlier stages in spermatogenesis that could have a role as selected messages in the early zygote (Miller et al. 1999, Ostermeier et al. 2002). No information is available to date on the gene sequence coding for the $\mu$ opioid receptor in equine species. Sequence analysis of the amplified fragment revealed a high degree of conservation when compared with human, bovine and rat homologous nucleotide regions.

To our knowledge, this study provides the first biochemical characterization of $\mu$-opioid receptor protein in mammalian sperm cells and it is the first to describe a Western blot analysis of this protein in the equine species.

\begin{tabular}{|c|c|c|}
\hline equine & --- & 35 \\
\hline bovine & ACACTAACATTCTCTCACECA ACGTGGTACTGGGAAAACETACTEAAAATCTGTGT:TT: & 675 \\
\hline buman & ACACTAACATTCTCTCATCEAACCTGETACTGGGAAAACGTAETEAAGATCTGTGT:IT: & 955 \\
\hline rat & 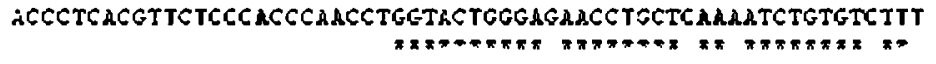 & 921 \\
\hline equine & aTCTTTGCCTTCATCATGCCTATCCTCATCATTACAGTGTGTTHFGGCTGATGATCIT & 95 \\
\hline bovine & АTCTTTGCCTTСATCATGCCTATCCTCATCATTACAGTGTGTTAFGGGCTGATGATCTTA & 935 \\
\hline human & АT-TTCGCCTTCATTATGCCAGTGCTCATCגTTACCGTGTGNTגOGGגCTGATGATCTTS & 1014 \\
\hline cat & 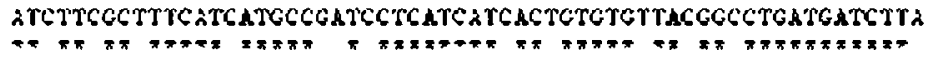 & 981 \\
\hline equine & CGCCTCAAGAGTTCCGCATGCTCTCTGGCTCCAAAGAAAAGACAGGAACTGCGAAGA & 155 \\
\hline bovine & CGCCTCAAGAGTGTCCGCATGCTCTCZGGCTCCAAAGAAAAGGACAGGAACCTGCEAMGA & 995 \\
\hline human & CGCCTCAAGAGTOTCCGCATGCTCTC RGGCTCCAAAGAAARGGHCAGGAATCTTCGADGO & 1074 \\
\hline rat & 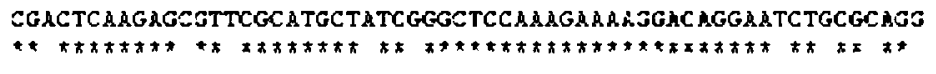 & 1041 \\
\hline equine & RTCACSACGATCOTGCTGCTGGTTGTGGCTOTCTTCATTCTCTGCTGCACGCCCATMCR: & 215 \\
\hline bovine & ATCACCAGGATGOTGCTGGTGGTTGTGGCTGTGTTCATTOTЕTGCTGGACGCCCATACAE & 1055 \\
\hline human & ¿TCACCAGGATGJTGCTGGTGGTGGTGGCTGTGTTCATCGTETGCTGGACTCCCATXCKE & 1134 \\
\hline cat & 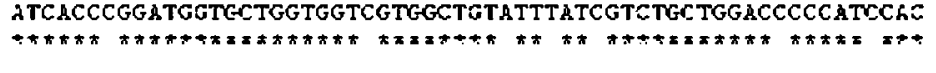 & 1101 \\
\hline equine & 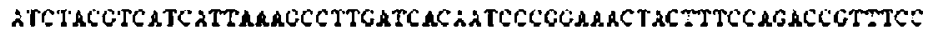 & 275 \\
\hline bovine & 2TCTACGTCATCATTAAAGCETTGATCAGAATCCCGGAAACTACTTCCAGACCGT:TEE & 1115 \\
\hline human & ATTTACGTCATEATTAAAGCETTGGT ACAATCECAGAAAGTACGTTCEAGACTGTITET & 1194 \\
\hline rat & 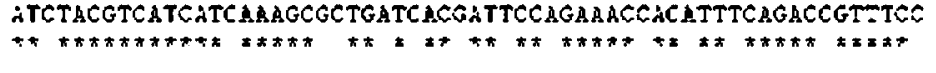 & 1161 \\
\hline equine & TGGCACTTCTCCATTGCTCTAGGTTATACCAACAGTTGCCTGAACCCCGTCCTTTATGCA & $\mathbf{3 . 3 5}$ \\
\hline bovine & TGGCACTTCZGCATTGCTCTAGGTTATACCAACAGTTGCCTCAACCCCGTCCTTTATGCA & 1175 \\
\hline human & TCCCACTTCTCCATTGCTCTACCTTACACAAACACCTGCGTCAACCCAGTCCTTTATGCA & 1254 \\
\hline rat & 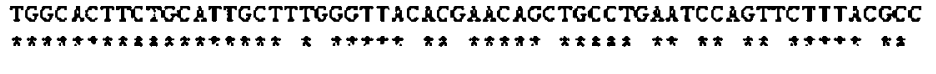 & 1221 \\
\hline equine & TTTCTGGATGAAAACTTCAAACGATGCTTCAGAGAGTTCTGTATCCCAACTTCCTCCACC & 395 \\
\hline bovine & TTTCTGGATGגkAACTTChhACGkTGCTTCAGAGAGTTCIGTATCCCAגCTTCCTCCACC & 1235 \\
\hline human & 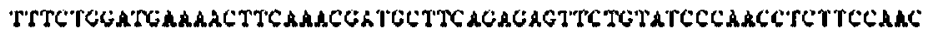 & 2314 \\
\hline cat & TTCCTGGATG A AACTTCA AGCGA TGCTTC AGAGAGTTCTGC ATCCС ACCTCGTCCACG & 1781 \\
\hline & 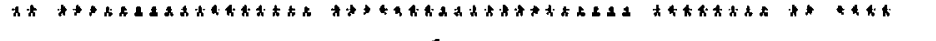 & \\
\hline equine & ATTGAGCAGCAAAACTCCACTCGAATTCGTCAGAACACTAGAGACC-ー- & 441 \\
\hline bovine & ATTGAGCAGCAAAACTCCACTCGÄTTCGTCAGAACACCAGAGACCACCCCTCCACAGCC & 1295 \\
\hline human & ATTGAGCALCAAACTCCACTCGARTTCGTCAGAACACTAGAGACCACCCCTCCACGGCC & 1374 \\
\hline cat & 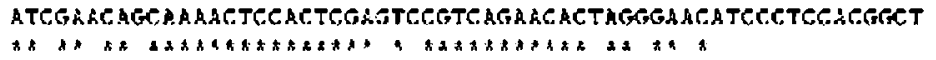 & 1.341 \\
\hline
\end{tabular}

Figure 2 Nucleotide sequence of the amplified third extracellular loop of the $\mu$-opioid receptor. The equine sequence is presented and aligned with human (GI, 459831), rat (GI, 437671) and bovine (GI, 4521325) $\mu$-opioid receptor cDNAs. Asterisks denote identical nucleotides. Primers used both in the RT-PCR and in sequencing reactions are indicated by arrows. 

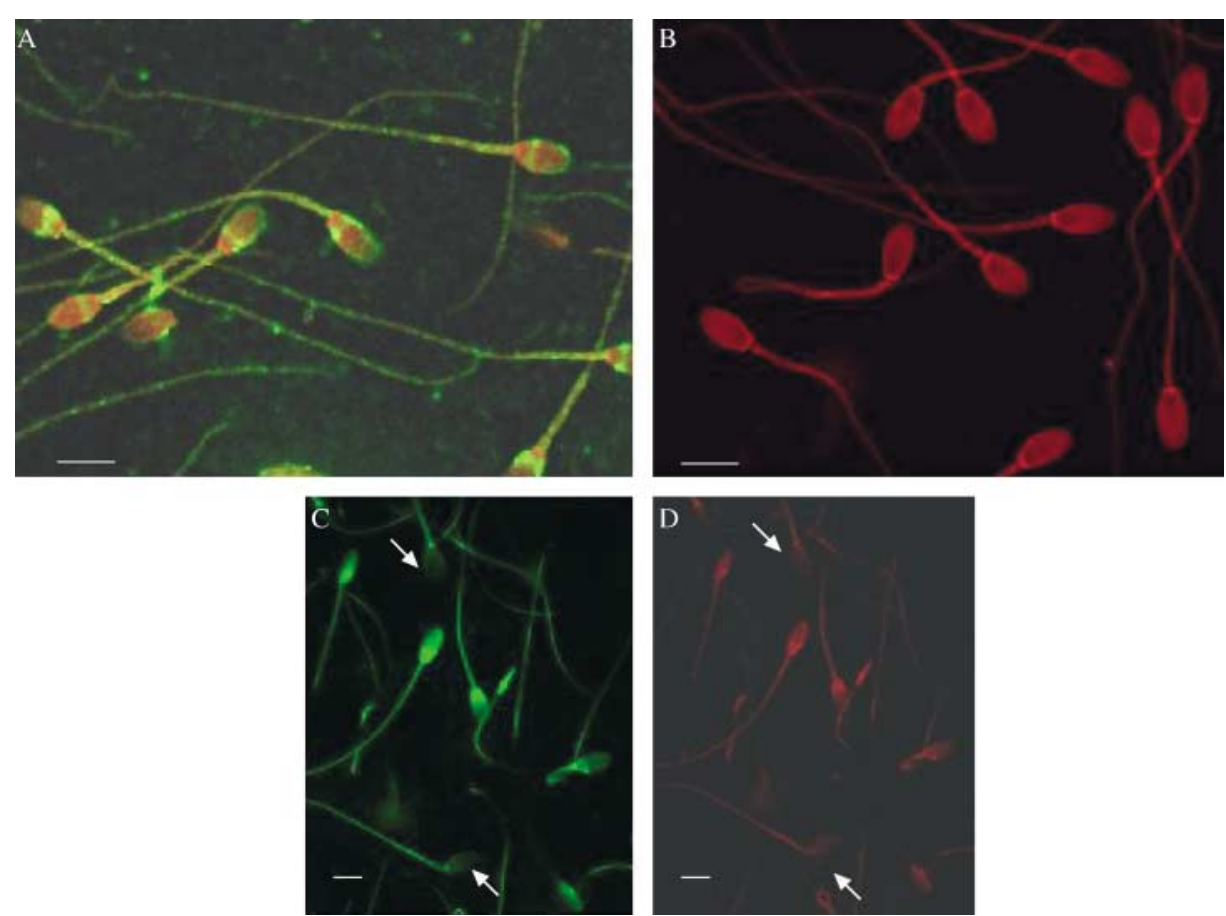

Figure 3 Confocal laser scanning photomicrographs to demonstrate the localization of the $\mu$-opioid receptor in equine sperm cells. Anti-MOR immunoreactivity evidenced by FITC staining is observed over the acrosomal region of the sperm head and on the tail. Cells were counterstained with Evans Blue (A). (B) Negative control. (C, D) $\mu$-Opioid receptor and PSA staining patterns in equine AR sperm cells. Cells were double-stained for $\mu$-opioid receptor, by using a TRITC-conjugated goat anti-rabbit IgG, and for the acrosome reaction, by using FITC-PSA. Paired immunofluorescence micrographs show sperm cells with PSA staining in green (C) and the $\mu$-opioid receptor stained in red (D). AR cells (arrows), showing no FITC-PSA staining at all or staining limited to the equatorial segment, are also negative for the $\mu$-opioid receptor staining on the head. Scale bars, $9.0 \mu \mathrm{m}$.

$\mu$-Opioid receptors in the rat brain were shown to have molecular masses ranging from 60 to $75 \mathrm{kDa}$, and indicative of a glycoprotein nature that, upon deglycosylation, down-shifts to a sharp band of $39 \mathrm{kDa}$ (for review see Chen et al. 1995). The existence of a glycosylated form of the $\mu$-opioid receptor was predicted based on previous reports in the literature (in Chinese hamster ovary $(\mathrm{CHO})$ cells (Chen et al. 1995) and in human embryonic kidney (HEK)-293 cells (Chaturvedi et al. 2001)) and on the presence of a typical $\mathrm{N}$-glycosylation consensus sequence located at the $\mathrm{N}$ terminus (Chaturvedi et al. 2000). The fact that in this study the 50 and $65 \mathrm{kDa}$ bands immunodetected in the equine sperm plasma membranes were not shifted to a lower molecular mass after PNGase $\mathrm{F}$ treatment indicates that the horse $\mu$-opioid receptor polypeptide is not $\mathrm{N}$-glycosylated. The possibility of O-linked glycosylation cannot be discarded. The molecular mass of the ram $\mu$-opioid receptor resulted in a $100 \mathrm{kDa}$ band, a size even higher than that of the horse $\mu$-opioid receptor (M Albrizio, unpublished observations). Further studies aimed at cloning and investigating the entire sequence of the equine $\mu$-opioid receptor cDNA will certainly provide an explanation for the molecular mass characterizing the horse $\mu$-opioid receptor as compared with other mammalian homologues.
Functional investigations concerned the effects of $\mathrm{Nx}$ on sperm cell motility and capacitation/acrosome reaction. The use of $\mathrm{Nx}$ was due to the well-documented high affinity of this molecule for the receptor (Minami and Satoh 1995, Reisine and Pasternak 1996). Nx was used at low $\left(10^{-8} \mathrm{M}\right)$ and high $\left(10^{-3} \mathrm{M}\right)$ doses since, in previous studies carried out on renal epithelial cells and on cumulus-oocyte complexes, we observed that $\mathrm{Nx}$ at low concentrations $\left(<10^{-6} \mathrm{M}\right)$ behaves as an antagonist of EOP action, whereas at high concentrations $\left(>10^{-6} \mathrm{M}\right)$ it seems to possess partial agonist effects at the opioid receptor (Di Sole et al. 2001, Dell'Aquila et al. 2002).

$\mathrm{Nx}$ at low doses $\left(10^{-8} \mathrm{M}\right)$ showed a positive effect on progressive motility, velocity and VCL after $5 \mathrm{~h}$ incubation, suggesting that it could have a stimulatory effect on sperm cell motility, depending on intracellular $\mathrm{Ca}^{2+}$ influx. $\mathrm{Nx}$ at high doses $\left(10^{-3} \mathrm{M}\right)$ was found to have a negative effect on all the motility parameters considered, excluding total motility, thus suggesting an inhibitory role on specific aspects of motility patterns. These data provide further support for the pharmacodynamic concept of the doserelated relative antagonist and agonist actions of $\mathrm{Nx}$ and are in agreement with the clinical evidence of the beneficial effects of low-dose Nx (Sciorsci et al. 2000). The CASA system for the evaluation of semen samples has been used in different species (for review see Verstegen 


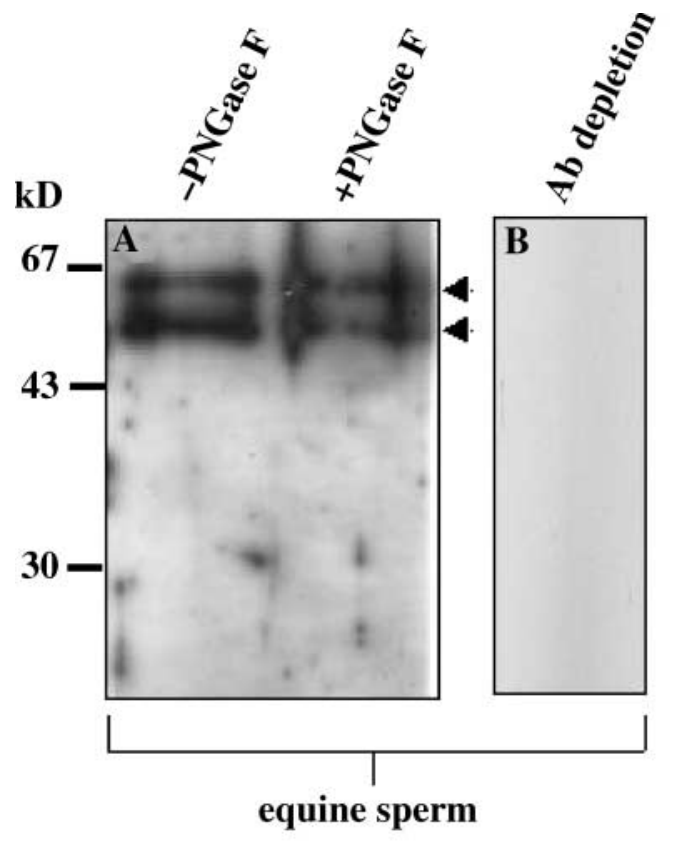

$\mu$-opioid receptor
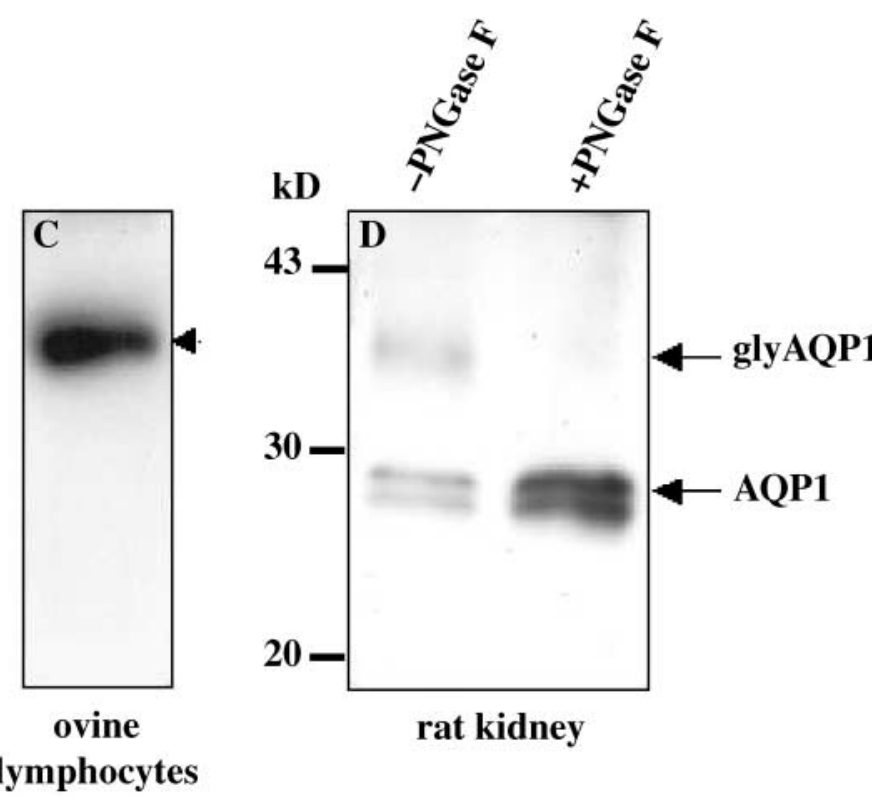

AQP1

Figure 4 Immunoblotting analysis of the $\mu$-opioid receptor in plasma membranes from stallion sperm cells. Blot with equine sperm cell plasma membranes incubated with antiserum to a peptide related to the third extracellular loop of the mouse $\mu$-opioid receptor. (A) Two bands of 50 and $65 \mathrm{kDa}$ were observed (arrows). No differences are observed between the immunoblotting profiles obtained before (-PNGase F) and after (+PNGase F) N-deglycosylation by PNGase F. (B) Negative control blot where the equine sperm cell plasma membranes were incubated with a solution where the primary antibody was adsorbed with a molar excess of the immunizing peptide. (C) Positive control showing the specificity of the $\mu$-opioid receptor antibodies incubated with a plasma membrane fraction prepared from sheep lymphocytes. The arrow indicates the $\mu$-opioid receptor band. (D) Control blot with rat renal cortex membranes with (+PNGase F) or without (-PNGase F) N-glycosidase treatment incubated with anti-AQP1 antibodies. As expected (Smith \& Agre 1991), the diffuse band ranging between 34 and $38 \mathrm{kDa}$ and representing the $\mathrm{N}$-glycosylated form of AQP1 (glyAQP1) is not observed in the PNGase F-treated membranes whereas the $28 \mathrm{kDa}$ band (core form of AQP1) is stronger than the corresponding band detected in the membrane fraction where the PNGase F was omitted. Results shown are representative of three separate experiments.

Table 1 Motility parameters in fresh equine spermatozoa incubated in the presence of Nx in Tyrode's medium.

\begin{tabular}{|c|c|c|c|c|}
\hline & \multicolumn{3}{|c|}{ Time point } & \multirow[b]{2}{*}{$P$ values } \\
\hline & h 0 & h 3 & h 5 & \\
\hline \multicolumn{5}{|c|}{ Total motility (\% of motile spermatozoa) } \\
\hline Control & $55.9 \pm 18.4$ & $50.0 \pm 10.9$ & $48.6 \pm 7.3$ & \\
\hline $\mathrm{N} \times 10^{-3} \mathrm{M}$ & $50.1 \pm 15.4$ & $39.9 \pm 11.4$ & $45.6 \pm 10.1$ & \\
\hline $\mathrm{N} \times 10^{-8} \mathrm{M}$ & $57.6 \pm 10.9$ & $42.8 \pm 14.8$ & $47.9 \pm 11.2$ & \\
\hline \multicolumn{5}{|c|}{ Progressive motility (\% of progressively motile spermatozoa) } \\
\hline Control & $19.0 \pm 9.0$ & $15.1 \pm 8.4^{\mathrm{a}}$ & $6.6 \pm 6.7 \mathrm{~d} *$ & \multirow{3}{*}{ a vs $b p<0.05 ;$ c vs $d^{*} p<0.05 ;$ c vs $d * * p<0.001$} \\
\hline $\mathrm{N} \times 10^{-3} \mathrm{M}$ & $13.3 \pm 12.5$ & $5.9 \pm 4.9^{b}$ & $2.5 \pm 2.5 d^{* *}$ & \\
\hline $\mathrm{N} \times 10^{-8} \mathrm{M}$ & $21.9 \pm 13.1$ & $14.9 \pm 13.0^{\mathrm{a}, \mathrm{b}}$ & $17.6 \pm 11.6^{\mathrm{C}}$ & \\
\hline \multicolumn{5}{|c|}{ Velocity $(\mu \mathrm{m} / \mathrm{sec})$} \\
\hline Control & $46.9 \pm 11.1$ & $29.9 \pm 6.0$ & $22.5 \pm 5.4^{\mathrm{b}}$ & \multirow{3}{*}{ a vs $b$ p $<0.001 ;$ b vs c $p<0.05 ;$ a vs c $p<0.0001$} \\
\hline $\mathrm{N} \times 10^{-3} \mathrm{M}$ & $38.4 \pm 11.0$ & $28.5 \pm 11.9$ & $16.0 \pm 3.0^{\mathrm{C}}$ & \\
\hline $\mathrm{N} \times 10^{-8} \mathrm{M}$ & $43.6 \pm 12.1$ & $34.9 \pm 14.4$ & $33.3 \pm 7.5^{\mathrm{a}}$ & \\
\hline \multicolumn{5}{|l|}{$\mathrm{VCL}(\mu \mathrm{m} / \mathrm{sec})$} \\
\hline Control & $55.0 \pm 12.9$ & $35.0 \pm 7.0$ & $27.3 \pm 5.5^{\mathrm{b}}$ & \multirow{3}{*}{ a vs b p $<0.01 ;$ b vs c $p<0.01 ;$ a vs c $p<0.0001$} \\
\hline $\mathrm{N} \times 10^{-3} \mathrm{M}$ & $48.8 \pm 14.9$ & $36.9 \pm 17.7$ & $18.8 \pm 4.7^{\mathrm{c}}$ & \\
\hline $\mathrm{N} \times 10^{-8} \mathrm{M}$ & $51.1 \pm 14.4$ & $38.6 \pm 16.0$ & $37.5 \pm 7.0^{\mathrm{a}}$ & \\
\hline \multicolumn{5}{|l|}{$\mathrm{ALH}(\mu \mathrm{m})$} \\
\hline Control & $2.8 \pm 0.6$ & $1.9 \pm 0.6$ & $1.6 \pm 0.2^{\mathrm{a}}$ & \multirow{3}{*}{ a vs $b p<0.05$} \\
\hline $\mathrm{N} \times 10^{-3} \mathrm{M}$ & $2.6 \pm 0.6$ & $2.0 \pm 1.0$ & $1.2 \pm 0.3^{b}$ & \\
\hline $\mathrm{N} \times 10^{-8} \mathrm{M}$ & $2.4 \pm 0.7$ & $2.1 \pm 0.3$ & $1.6 \pm 0.4^{\mathrm{a}}$ & \\
\hline
\end{tabular}

VCL, curvilinear velocity; ALH, amplitude of lateral head displacement. 

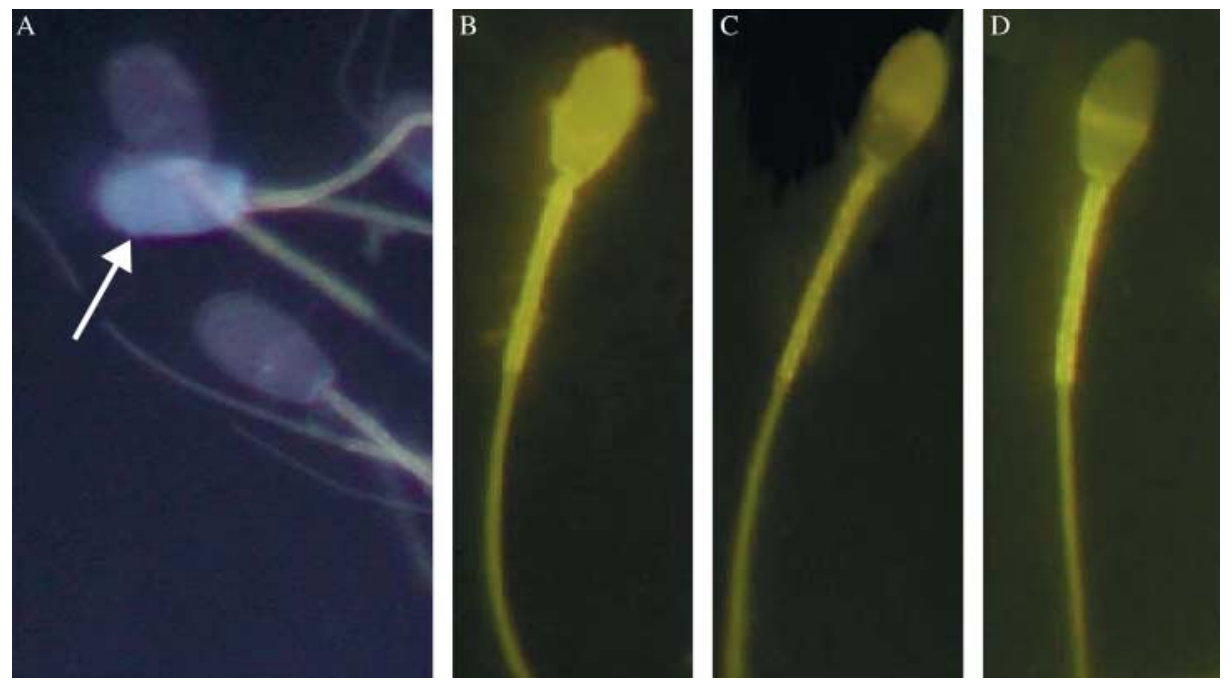

Figure 5 Fluorescent H258/CTC patterns detected in stallion spermatozoa. (A) Dead cell stained positive for H258 (blue fluorescence, arrow). These cells, recorded as dead, were not assessed for their CTC-staining pattern. (B) The whole sperm head shows bright fluorescence, indicative of a live non-capacitated (L/NC) spermatozoa. (C) The acrosomal region of the sperm head is brightly fluorescent but the post-acrosomal region is not; this denotes a live capacitated, acrosome-intact (L/C) spermatozoon. (D) The acrosomal region of the sperm head is nonfluorescent with or without a fluorescent post-acrosomal region; this indicates live capacitated, acrosome-reacted (L/AR) spermatozoa.

et al. 2002) and for different purposes, although relatively few studies have been reported in stallion sperm cells (for review see Quintero-Moreno et al. 2003). The values of VCL and ALH reported in our study are not indicative of hyperactivation of sperm cells under the experimental conditions examined. Only two studies have described the use of the CASA system to assess hyperactivation in horse sperm cells (Alm et al. 2001, Rathi et al. 2001). Rathi et al. (2001) defined spermatozoa with a VCL value of $>180 \mu \mathrm{m} / \mathrm{s}$ and a ALH value of $>12 \mu \mathrm{m}$ as hyperactive. The absence of sperm cells showing a hyperactivation pattern led us to plan further investigations to determine the optimal $\mathrm{Nx}$ concentration and length of incubation.

One of the goals of this study was to evaluate the effects of $\mathrm{Nx}$ on the induction of capacitation and the acrosome reaction, in consideration of the low efficiency reported to date of capacitation in vitro in stallion spermatozoa (for review see Alm et al. 2001). Our data showed that $\mathrm{Nx}$ at $10^{-8} \mathrm{M}$ significantly stimulated capacitation $(P<0.01)$

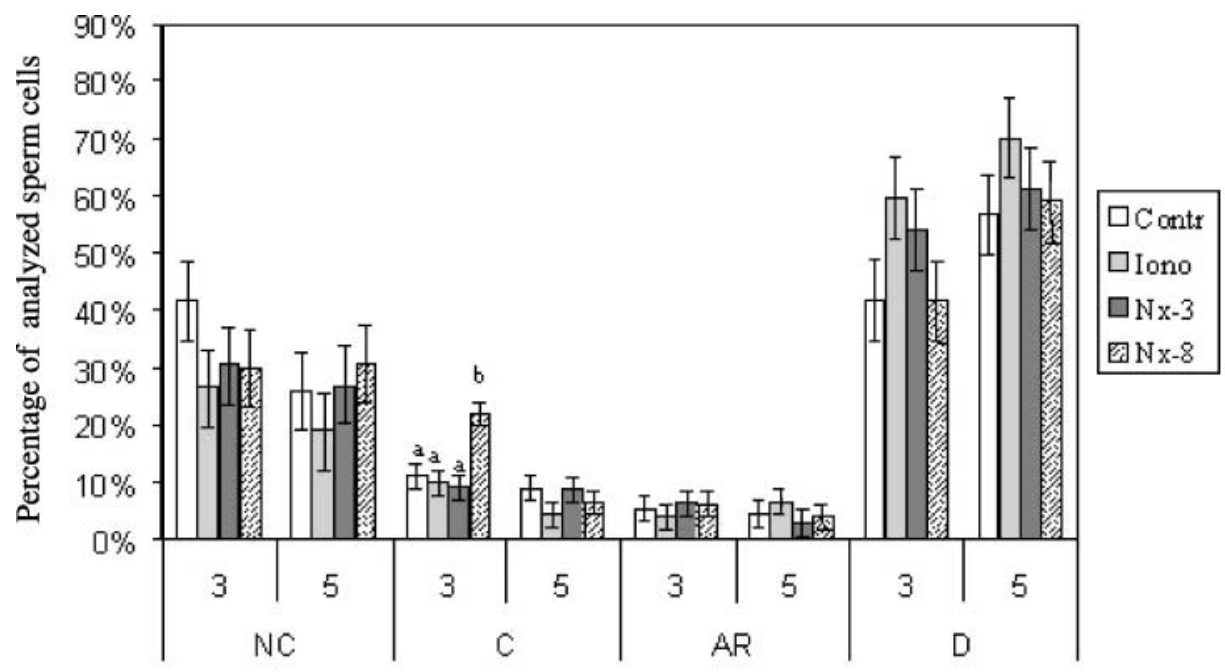

Figure 6 Comparison of the effects of $\mathrm{Nx}$ and calcium ionophore $\mathrm{A} 23187$ on capacitation, acrosomal status and viability of equine spermatozoa. Sperm cells were incubated at $37^{\circ} \mathrm{C}$ under $5 \% \mathrm{CO}_{2}$ with $10^{-3} \mathrm{M} \mathrm{Nx}(\mathrm{Nx}-3), 10^{-8} \mathrm{M} \mathrm{Nx}(\mathrm{Nx}-8), 1 \mu \mathrm{M} \mathrm{A} 23187$ (Iono) and without additive (Contr). At 3 and $5 \mathrm{~h}$ viability and the state of capacitation/acrosome reaction were assessed by H258/CTC staining. Trends of the least-square means of the different cell percentages on the total number of cells are expressed at the two analyzed times. Different patterns of spermatozoa were indicated as follows: C, live capacitated; NC, live non-capacitated; AR, live acrosome-reacted; D, dead. Standard errors are indicated by bars. Means with different letters differ significantly $(P<0.01)$. 
after $3 \mathrm{~h}$ incubation, indicating that the $\mu$-opioid receptor participates in the signaling associated with the induction of capacitation and the acrosome reaction, probably via an increase in intracellular $\mathrm{Ca}^{2+}$. $\mathrm{Nx}$ had no effects on sperm cell acrosomal status. In all the experimental conditions examined high mortality was observed using the combined H258/CTC staining. Nx was also not effective on sperm cell viability. Incubation with A23187 for $3 \mathrm{~h}$ tended to decrease the percentage of NC cells compared with the control. This was in line with data reported in previous studies with fresh stallion semen (Varner et al. 1987, Christensen et al. 1996, Pommer et al. 2002, Rathi et al. 2003). However, the decrease in NC cells observed in our study was not related to an increase in cells showing the $C$ or the AR pattern but to an increase in the percentage of D cells, although not statistically significant. Previous studies reported a positive effect of A23187 on the occurrence of acrosome reactions in stallion spermatozoa but different experimental conditions (A23187 concentration or incubation medium) or different evaluation systems were used (Varner et al. 1987, Christensen et al. 1996, Pommer et al. 2002, Rathi et al. 2003). Previous investigations using A23187 as a method of stallion sperm capacitation for in vitro fertilization supported its positive effect on the occurrence of capacitation and acrosome reaction. All the same, the concentrations of A23187 used for capacitation were different in the various reports (for review see Alm et al. 2001) and in our study. Data obtained in these experiments demonstrated that $\mathrm{Nx}$ at $10^{-8} \mathrm{M}$ acted as an inducer of capacitation, maintaining comparable levels of sperm cell viability to those observed in control conditions.

In conclusion, the results obtained in this study demonstrate (1) the expression of the $\mu$-opioid receptor gene and the corresponding protein product in equine spermatozoa, (2) a confirmation of the high degree of conservation of the examined region of the $\mu$-receptor cDNA, as revealed by comparing the equine nucleotide sequence with those of human, bovine and rat samples, (3) a biochemical characterization of the $\mu$-opioid receptor that was found to be peculiar in this cell type and for the equine species and (4) a possible role exerted by EOP in modulating sperm cell activities, mediated by the $\mu$-opioid receptor with effects on motility and capacitation.

\section{Acknowledgments}

We thank Professor A. Caroli (Dipartimento di Sanità e Benessere degli Animali, Università di Bari, Italy) for her help in the statistical analysis of H258/CTC data and Anthony Green for kindly revising the English. Support from MIUR (Ministero Istruzione, Università e Ricerca, Italy) COFINPRIN 2001, 2002 and CEGBA (Centro Eccellenza Genomica Comparata Università di Bari, Italy) is gratefully acknowledged. Part of this work was presented at the First Congress of the Italian Society of Animal Reproduction, 10-12 April 2003, Vico Equense, Naples, Italy.

\section{References}

Alm H, Torner H, Blottner S, Nümberg G \& Kanitz W 2001 Effect of sperm cryopreservation and treatment with calcium ionophore or heparin on in vitro fertilization of horse oocytes. Theriogenology $56817-829$.

Baldi E, Luconi M, Bonaccorsi L \& Forti G 2002 Signal transduction pathways in human spermatozoa. Journal of Reproductive Immunology 53 121-131.

Bourinet E, Song TW, Stea A \& Snurch TP 1996 Determinants of the $G$ protein dependent opioid modulation of neuronal calcium channels. PNAS 93 1486-1491.

Bray C, Son JM \& Meizel S 2002 A nicotinic acetylcholine receptor is involved in the acrosome reaction of human sperm initiated by recombinant human ZP3. Biology of Reproduction 67 782-788.

Calamita G, Mazzone A, Cho YS, Valenti G \& Svelto M 2001 Expression and localization of the Aquaporin-8 water channel in rat testis. Biology of Reproduction 64 1660-1666.

Chaturvedi K, Shahrestanifar M \& Howells RD $2000 \mu$ Opioid receptor: role for the amino terminus as a determinant of ligand binding affinity. Molecular Brain Research 76 64-72.

Chaturvedi K, Bandari P, Chinen N \& Howells RD 2001 Proteasome involvement in agonist-induced down-regulation of $\mu$ and $\delta$ opioid receptors. Journal of Biological Chemistry 276 12345-12355.

Chen C, Xue JC, Zhu J, Chen YW, Kunapuli S, Kim de Riel J \& Liu-Chen LY 1995 Characterization of irreversible binding of $\beta$-Funaltrexamine to the cloned rat $\mu$-opioid receptor. Journal of Biological Chemistry 270 17866-17870.

Cheng FP, Gadella BM, Voorhout WF, Fazeli A, Bevers MM \& Colenbrander B 1998 Progesterone-induced acrosome reaction in stallion spermatozoa is mediated by a plasma membrane progesterone receptor. Biology of Reproduction 59 733-742.

Christensen P, Whitefield CH \& Parkinson TJ 1996 In vitro induction of acrosome reaction in stallion spermatozoa by heparin and A23187. Theriogenology 45 1201-1210.

Connor M, Schuller A, Pintar JE \& Christie MJ 1999 Mu-opioid receptor modulation of calcium channel current in periaqueductal gray neurons from C57B16/J mice and mutant mice lacking MOR-1. British Journal of Pharmacology 126 1553-1558.

Dell'Aquila ME, Casavola V, Reshkin SJ, Albrizio M, Guerra L, Maritato F \& Minoia P 2002 Effects of $\beta$-endorphin and Naloxone on in vitro maturation of bovine oocytes. Molecular Reproduction and Development 63 210-222.

Di Sole F, Guerra L, Bagorda A, Reshkin SJ, Albrizio M, Minoia P \& Casavola V 2001 Naloxone inhibits A6 cell $\mathrm{Na}(+) / \mathrm{H}(+)$ exchange by activating protein kinase $\mathrm{C}$ via the mobilization of intracellular calcium. Experimental Nephrology 9 341-348.

Fabbri A, Tsai-Morris CH, Luna S, Fraioli F \& Dufau ML 1985 Opiate receptors are present in the rat testis. Identification and localization in Sertoli cells. Endocrinology 117 2544-2546.

Feigenbaum JJ \& Howard SG 1997 Effects of naloxone on amphetamine induced striatal dopamine release in vivo: a microdialysis study. Life Sciences 60 1659-1668.

Flesch FM \& Gadella BM 2000 Dynamics of the mammalian sperm plasma membrane in the process of fertilization. Biochimica et Biophysica Acta 1469 197-235.

Hunter RHF 1997 Sperm dynamics in the female genital tract: interactions with the Fallopian tube microenvironments. In Microscopy of Reproduction and Development: a Dynamic Approach, pp 35-45. Ed. PM Motta. Rome: Antonio Delfino Editore.

Jagannathan S, Publicover SJ \& Barratt CLR 2002 Voltage-operated calcium channels in male germ cells. Reproduction 123 203-215.

Miller D, Briggs D, Scoweden H, Hamlington J, Rollinson S, Lilford R \& Krawetz SA 1999 A complex population of RNAs exists in human ejaculated spermatozoa: implications for understanding molecular aspects of spermiogenesis. Gene 237 385-392.

Minami M \& Satoh M 1995 Molecular biology of the opioid receptors: structures, functions and distributions. Neuroscience Research 23 121-145. 
Neild DM, Gadella DM, Caves MG, Miragaya MH, Colenbrander B \& Aguero A 2003 Membrane changes during different stages of a freeze-thaw protocol for equine semen cryopreservation. Theriogenology 59 1693-1705.

Odeh AI, Dascanio JJ, Caceci T, Bowen J \& Eng LA 2003 Effect of platelet-activating factor (PAF) on stallion sperm motility, capacitation and the acrosome reaction. Reproduction $\mathbf{1 2 6}$ 605-613.

Ostermeier GC, Dix DJ, Miller D, Khatri P \& Krawetz SA 2002 Spermatozoal RNA profiles of normal fertile men. Lancet $\mathbf{3 6 0}$ $772-777$.

Pommer AC, Linfor JJ \& Meyers SA 2002 Capacitation and acrosomal exocytosis are enhanced by incubation of stallion spermatozoa in a commercial semen extender. Theriogenology $\mathbf{5 7}$ $1493-1501$

Quintero-Moreno A, Mirò J, Teresa Rigau A \& Rodriguez-Gil JE 2003 Identification of sperm subpopulations with specific motility characteristics in stallion ejaculates. Theriogenology $\mathbf{5 9}$ 1973-1990.

Rathi R, Colenbrander B, Bevers MM \& Gadella BM 2001 Evaluation of in vitro capacitation of stallion spermatozoa. Biology of Reproduction $65462-470$.

Rathi R, Colenbrander B, Stout TA, Bevers MM \& Gadella BM 2003 Progesterone induces acrosome reaction in stallion spermatozoa via a protein tyrosine kinase dependent pathway. Molecular Reproduction and Development 64 120-128.

Reisine T \& Pasternak G 1996 Opioid analgesics and antagonists. In The Pharmacological Basis of Therapeutics, pp 521-555. Eds. JG Hardman, LE Limbird \& A Goodman Gilman. New York: McGraw-Hill.

Ren D, Navarro B, Perez G, Jackson AC, Hsu S, Shi Q, Tilly JL \& Clapham DE 2001 A sperm ion channel required for sperm motility and male fertility. Nature 413 603-609.

Roser JF 2001 Endocrine and paracrine control of sperm production in stallions. Animal Reproduction Science 68 139-151.
SAS 1988 SAS/STATC User's guide, release 6.03 editionCary. NC: Institute Inc.

Sciorsci RL, Bianchi P \& Minoia P 2000 High levels of endorphin and related pathologies of veterinary concern. A review. Immunopharmacology and Immunotoxicology 22 575-626.

Smith BL \& Agre P 1991 Erythrocyte $M_{r}$ 28,000 transmembrane protein exists as a multisubunit oligomer similar to channel proteins. Journal of Biological Chemistry 266 6407-6415.

Spivak CE, Boglan CL, Seidleck BK, Hirshbein LD, Blaschak CJ, Uhl GR \& Surratt CK 1997 Naloxone activation of mu-opioid receptors mutated at a histidine residue lining the opioid binding cavity. Molecular Pharmacology 52 983-992.

Varner DD, Ward CR, Storey BT \& Kenney RM 1987 Induction and characterization of acrosome reaction in equine spermatozoa. American Journal of Veterinary Research 48 1383-1389.

Verstegen J, Iguer-Ouada M \& Onclin K 2002 Computer assisted semen analyzer in andrology research and veterinary practice. Theriogenology 57 149-179.

Xue JC, Chen C, Zhu J, Kunapuli SP, De Riel JK, Yu L \& Liu-Chen LY 1995 The third extracellular loop of the mu opioid receptor is important for agonist selectivity. Journal of Biological Chemistry 270 12977-12979.

Yanagimachi R 1994 Mammalian fertilization. In The Physiology of Reproduction, pp 189-317. Eds E Knobil \& JD Neill. New York: Raven Press.

Zadina JE, Hackler L, Ge LJ \& Kastin AJ 1997 A potent and selective endogenous agonist for the mu-opiate receptor. Nature $\mathbf{3 8 6}$ 499-502.

Received 20 April 2004

First decision 22 June 2004

Revised manuscript received 27 July 2004

Accepted 17 August 2004 